\title{
Mannan-Binding Lectin Levels and Activity Are Not Altered in Atopic Dermatitis Patients with a History of Eczema Herpeticum
}

\author{
Kemp W. Bundy, ${ }^{1}$ Laura Y. McGirt, ${ }^{2}$ Lora G. Bankova, ${ }^{2}$ Andreas Wollenberg, ${ }^{3}$ Lisa A. Beck,, 4 \\ and Anna De Benedetto ${ }^{1,4}$ \\ ${ }^{1}$ Division of Allergy, Immunology, Rheumatology, University of Rochester Medical Center, Rochester, NY 14642, USA \\ ${ }^{2}$ Department of Dermatology, Johns Hopkins University, Baltimore, MD 21205, USA \\ ${ }^{3}$ Department of Dermatology and Allergy, Ludwig Maximilian University of Munich, 80539 Munich, Germany \\ ${ }^{4}$ Department of Dermatology, University of Rochester Medical Center, 601 Elmwood Avenue, P.O. Box 697, Rochester, \\ NY 14642, USA
}

Correspondence should be addressed to Anna De Benedetto, anna_debenedetto@urmc.rochester.edu

Received 18 July 2011; Accepted 23 August 2011

Academic Editor: Elizabeth Helen Kemp

Copyright (c) 2011 Kemp W. Bundy et al. This is an open access article distributed under the Creative Commons Attribution License, which permits unrestricted use, distribution, and reproduction in any medium, provided the original work is properly cited.

\begin{abstract}
Background. Eczema herpeticum (EH) is a potentially serious, systemic complication in subjects with atopic dermatitis (AD) caused by herpes simplex virus (HSV). The innate immune dysregulation that predisposes these subjects to cutaneous viral infections is not well understood. We tested the hypothesis that defects in mannan-binding lectin (MBL) may be associated with an increased risk of EH. Methods. We evaluated serum MBL levels and functional activity in 13 AD subjects with a history of $\mathrm{EH}(\mathrm{EH}+)$ and $21 \mathrm{AD}$ subjects with no history of $\mathrm{EH}(\mathrm{EH}-)$. MBL levels were detected by enzyme immunoassay. MBL pathway functional activity was evaluated by determining MBL C4b deposition capacity. Results. We found no statistical difference in MBL serum levels or function between $\mathrm{EH}+$ and $\mathrm{EH}$ - groups. Conclusion. Considering the limitations of this study (e.g., small samples size) our findings suggest that MBL defects do not play a role in $\mathrm{EH}$.
\end{abstract}

\section{Introduction}

Atopic dermatitis (AD) is the most common chronic, inflammatory skin disease. Although rare, one of the most severe complications of $\mathrm{AD}$ is a widely disseminated cutaneous infection with HSV, called eczema herpeticum (EH) [1]. Episodes of $\mathrm{EH}$ can be complicated by keratoconjunctivitis and viremia, leading to multiple organ involvement including meningitis and encephalitis. This makes $\mathrm{EH}$ one of the few true emergencies in dermatology [2].

Recently, it has been shown that AD subjects with a history of EH have a more severe phenotype as compared to $\mathrm{AD}$ subjects without a history of this viral complication. $\mathrm{ADEH}+$ patients have greater disease severity index score, greater allergen sensitization, and higher total IgE levels and peripheral eosinophilia [3].

The major hypothesis put forth to explain $\mathrm{AD}$ subjects' susceptibility to HSV and other viral infections is that they have one or more defects in the innate immune system. Thus far, the specific mechanism responsible for this condition has not been determined. Numerous publications have documented that the epidermis of $\mathrm{AD}$ subjects has reduced expression of antimicrobial proteins. Howell et al. [4] found that the LL-37-deficient (Clnp-/-) mice had greater HSV replication on the skin surface than wild-type mice, suggesting that the lack of this antimicrobial peptide may provide an explanation for $\mathrm{AD}$ patients' predisposition to EH. Another hypothesis contends that the impaired recruitment and function of plasmacytoid dendritic cells (PDC), which produce antiviral type 1 interferons, would predispose $\mathrm{AD}$ subjects to viral skin infections [1]. Recently, we have also highlighted that the greater viral susceptibility may be related to a defect in epidermal tight junctions which is observed in $\mathrm{AD}$ subjects [5].

There is preliminary epidemiologic evidence to suggest that Mannan-Binding Lectin (MBL) is important for 


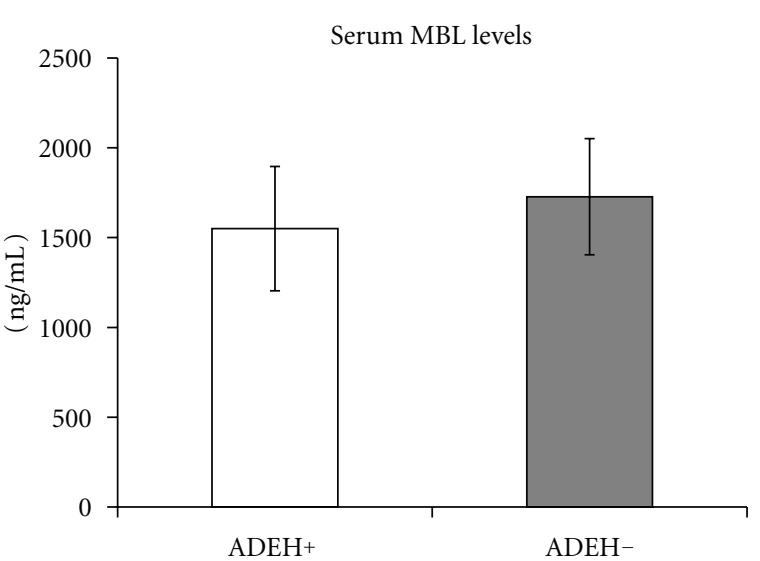

(a)

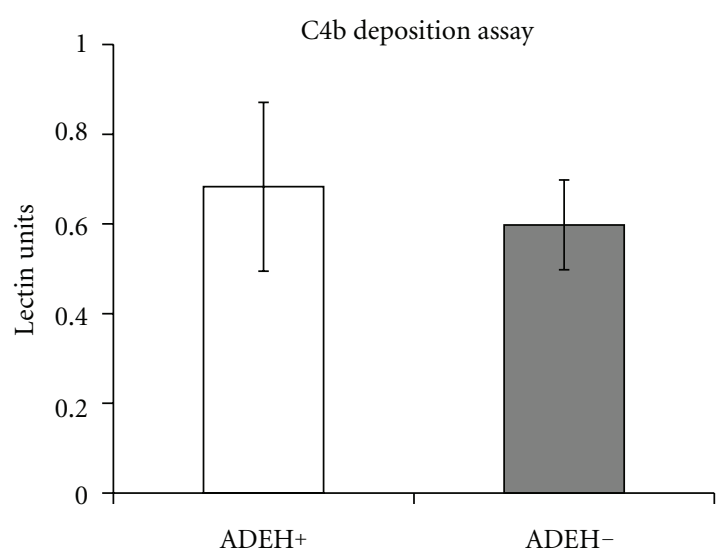

(b)

FIGURE 1: Mannan-binding lectin levels and activity in atopic dermatitis patients with and without a history of eczema herpeticum are not different. (a) Serum levels of MBL (ng/mL; ref. range $>200 \mathrm{ng} / \mathrm{mL}$ ) and (b) MBL functional activity (lectin units; ref. range > 0.2 lectin units $)$ in $\mathrm{ADEH}+(n=13)$ or $\mathrm{ADEH}-(n=21)$ patients. Red line represents lower limit of the normal reference range.

clearance of several common viruses (hepatitis B, HIV, and influenza A) [6]. In this study we tested the hypothesis that defects in MBL level or activity may be associated with an increased risk for $\mathrm{EH}$.

MBL, a soluble molecule from the collectin family of pathogen-related receptors, is a C-type lectin of hepatic origin that binds and circulates in a complex with MBLassociated serine proteases (MASPs). MBL-MASP2 initiates complement activation and microbial opsonization resulting in phagocytosis of foreign pathogens.

The expression of functional MBL protein is largely genetically determined [7]. Serum MBL deficiency has been observed in 10 to $15 \%$ of Caucasians with significantly higher percentages reported in subjects of African or South American Indian descent [6]. Such deficiencies and their variant alleles have been associated with increased susceptibility to bacterial infections in neutropenic subjects, poorer prognosis in cystic fibrosis patients, or more severe meningococcal disease [6].

Interestingly, Seppänen et al. [8] demonstrated an $M B L 2$ (MBL gene) structural variant genotype $(\mathrm{A} / \mathrm{O}$ or $\mathrm{O} / \mathrm{O})$ that was more common among the patients with recurrent HSV-2 infection compared with healthy controls or controls positive for HSV-2 antibodies. A recent report highlights a clear association between extremely low MBL levels and the BB MBL haplotype in several members of a Turkish family who also suffered from recurrent staphylococcal infections (skin, ear, and airway) and a pruritic, eczematous dermatitis [9]. Two genetic studies have reported conflicting results regarding MBL polymorphisms and their associations with AD. Brandrup et al. [9] did not find an association between the MBL B allele and AD susceptibility in a Japanese population. In contrast, a study of Brazilian $\mathrm{AD}$ subjects demonstrated that the three exon 1 variants $(\mathrm{B}, \mathrm{C}$, and $\mathrm{D})$ were observed more frequently than in a healthy control population [10].

No studies have evaluated MBL levels or genotypes in $\mathrm{AD}$ $\mathrm{EH}+$ subjects.

\section{Materials and Methods}

2.1. Study Population. This study received approval from the Johns Hopkins Medical Institution IRB as well as by the ethics committee of the Department of Dermatology and Allergy, Ludwig Maximilian University, Munich, Germany. Written informed consent was obtained. Serum was collected from adult subjects whose diagnosis of $\mathrm{AD}$ was made by a dermatologist who specializes in the care of $\mathrm{AD}$ (LAB and $\mathrm{AW} ; n=34)$. AD subjects were categorized as $\mathrm{EH}+$ if the subject had an episode of EH that was observed by one of the two dermatologists and for which the presence of HSV was confirmed by one of the following means (culture, Tzanck smear, PCR, or immunofluorescence assay). Subjects in the control $\mathrm{AD}$ group were selected if they had no history of $\mathrm{EH}$ as assessed by a careful history (EH-) and had never been prescribed systemic antiviral therapy.

2.2. MBL Serum Levels and Functional Assay. Serum MBL levels were detected by enzyme immunoassay using monoclonal antibody against the oligomeric MBL carbohydratebinding domain. MBL pathway functional activity was evaluated indirectly by determining MBL C4b deposition capacity with an anti-human $\mathrm{C} 4$ monoclonal antibody. Both of these studies were performed at IBT reference laboratory (Lenexa, Kansas).

2.3. Statistical Analysis. Differences between groups were evaluated using a 2-tailed, unpaired $t$-test. A $P$ value of $\leq 0.05$ was considered statistically significant. Data were expressed as mean \pm SEM.

\section{Results and Discussion}

The EH- cohort $(n=21)$ had a mean age of $30 \pm 4$ years and 16 of 21 subjects $(76 \%)$ were female, whereas the EH+ cohort $(n=13)$ had a mean age of $36 \pm 5$ years and 4 of 13 
subjects (31\%) were female. The mean serum MBL level (ref. range $>200 \mathrm{ng} / \mathrm{mL}$ ) for $\mathrm{EH}-$ patients was $1727 \pm 323 \mathrm{ng} / \mathrm{mL}$ and for $\mathrm{EH}+$ patients was $1549 \pm 346 \mathrm{ng} / \mathrm{mL}(P=0.703)$ (Figure 1(a)). MBL functional activity as measured by $\mathrm{C} 4 \mathrm{~b}$ deposition assay (ref. range $>0.2$ lectin units) for $\mathrm{EH}-$ patients was $0.6 \pm 0.1$ lectin units and for $\mathrm{EH}+$ patients was $0.7 \pm 0.1$ lectin units $(P=0.685)$ (Figure $1(b))$. There was no statistically significant difference in MBL levels or functional activity between the two $\mathrm{AD}$ groups $(\mathrm{EH}-$ and $\mathrm{EH}+)$.

Our study demonstrates that AD subjects with a history of EH had similar levels and functional activity of serum $\mathrm{MBL}$ as AD subjects with no history of EH. This suggests that MBL deficiency or defects in this pathway are not likely to be a susceptibility factor for the development of EH. Evaluation of this in a larger cohort of AD patients, as well as in ADEH+ subjects during an acute $\mathrm{EH}$ event, would be needed to solidify this conclusion.

\section{Conclusions}

Clinical studies aiming to clarify the pathogenesis of $\mathrm{EH}$ in $\mathrm{AD}$ are limited by the low prevalence of the disease and often by the very young age of patients involved. Additionally, a clinical test that can carefully characterize the subphenotype after the acute event is not available, thus making it difficult to study very well-characterized populations. Considering these limitations, we believe that any data, even negative, should be made available to other investigators in the field. Further work is needed to determine the precise defect(s) that predispose AD patients to this potentially lifethreatening viral skin infection.

\section{Conflict of Interests}

The authors have no conflict of interests to declare.

\section{Acknowledgments}

This work was funded by National Institute of Health Funding (NO1 AI40029 (L. A. Beck) and Training grantDHHS/PHS/NIH 5 T32 AR007472-21 (Kirschstein-NRSA; A. De Benedetto)) and by a National Eczema Association research grant (A. De Benedetto).

\section{References}

[1] A. Wollenberg and E. Klein, "Current aspects of innate and adaptive immunity in atopic dermatitis," Clinical Reviews in Allergy and Immunology, vol. 33, no. 1-2, pp. 35-44, 2007.

[2] A. Wollenberg, S. Wetzel, W. H. C. Burgdorf, and J. Haas, "Viral infections in atopic dermatitis: pathogenic aspects and clinical management," Journal of Allergy and Clinical Immunology, vol. 112, no. 4, pp. 667-674, 2003.

[3] L. A. Beck, M. Boguniewicz, T. Hata et al., "Phenotype of atopic dermatitis subjects with a history of eczema herpeticum," Journal of Allergy and Clinical Immunology, vol. 124, no. 2, pp. 260-269, 2009.

[4] M. D. Howell, A. Wollenberg, R. L. Gallo et al., "Cathelicidin deficiency predisposes to eczema herpeticum," Journal of
Allergy and Clinical Immunology, vol. 117, no. 4, pp. 836-841, 2006.

[5] A. De Benedetto, M. K. Slifka, N. M. Rafaels et al., "Reductions in claudin-1 may enhance susceptibility to herpes simplex virus 1 infections in atopic dermatitis," Journal of Allergy and Clinical Immunology, vol. 128, no. 1, pp. 242-246, 2011.

[6] L. H. Bouwman, B. O. Roep, and A. Roos, "Mannose-binding lectin: clinical implications for infection, transplantation, and autoimmunity," Human Immunology, vol. 67, no. 4-5, pp. 247256, 2006.

[7] W. K. Eddie Ip, K. Takahashi, R. Alan Ezekowitz, and L. M. Stuart, "Mannose-binding lectin and innate immunity," Immunological Reviews, vol. 230, no. 1, pp. 9-21, 2009.

[8] M. Seppänen, M. L. Lokki, M. Lappalainen et al., "Mannosebinding lectin 2 gene polymorphism in recurrent herpes simplex virus 2 infection," Human Immunology, vol. 70, no. 4, pp. 218-221, 2009.

[9] F. Brandrup, K. M. Homburg, P. Wang, P. Garred, and H. O. Madsen, "Manna-binding lectin deficiency associated with recurrent cutaneous abscesses, prurigo and possibly atopic dermatitis. A family study," British Journal of Dermatology, vol. 140, no. 1, pp. 180-181, 1999.

[10] L. A. C. Brandã, R. L. Guimarã, M. Carrera et al., "MBL2 functional allelic variants and increased risk for the development of atopic dermatitis in Brazilian children," Archives of Dermatology, vol. 144, no. 3, pp. 412-413, 2008. 


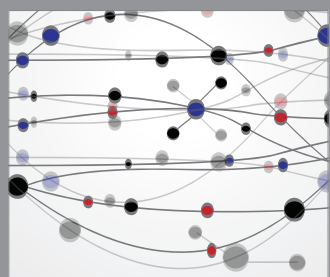

The Scientific World Journal
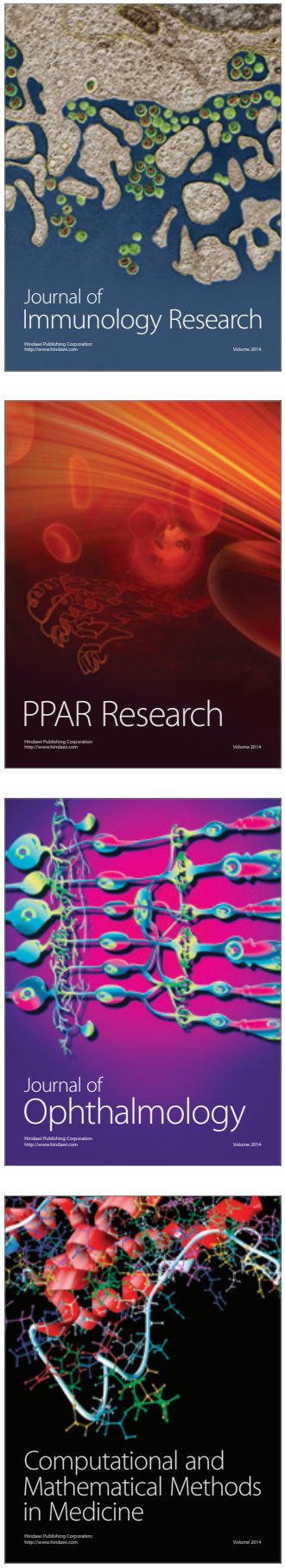

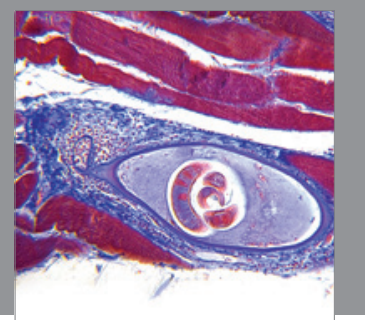

Gastroenterology

Research and Practice
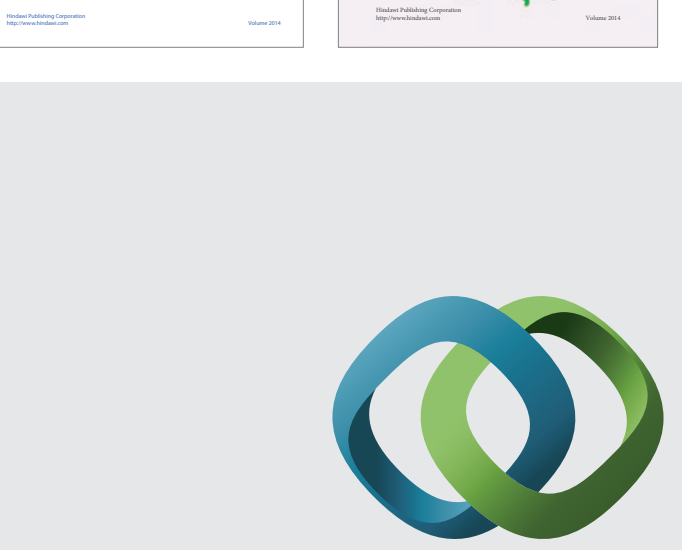

\section{Hindawi}

Submit your manuscripts at

http://www.hindawi.com
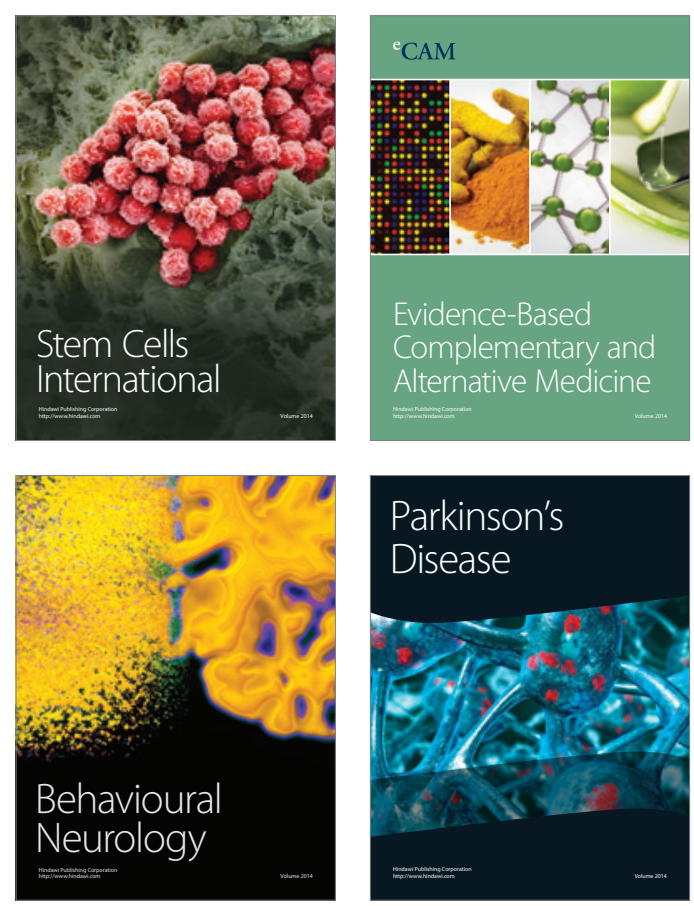

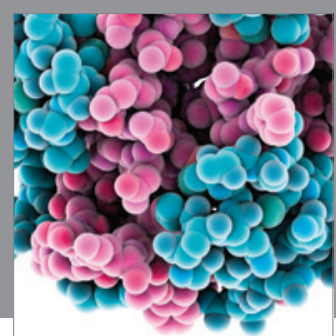

Journal of
Diabetes Research

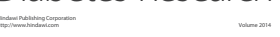

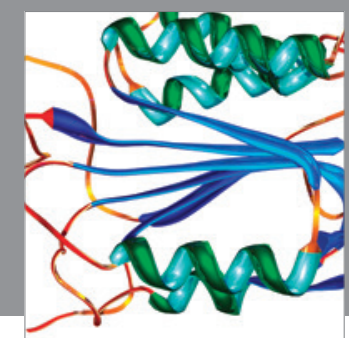

Disease Markers
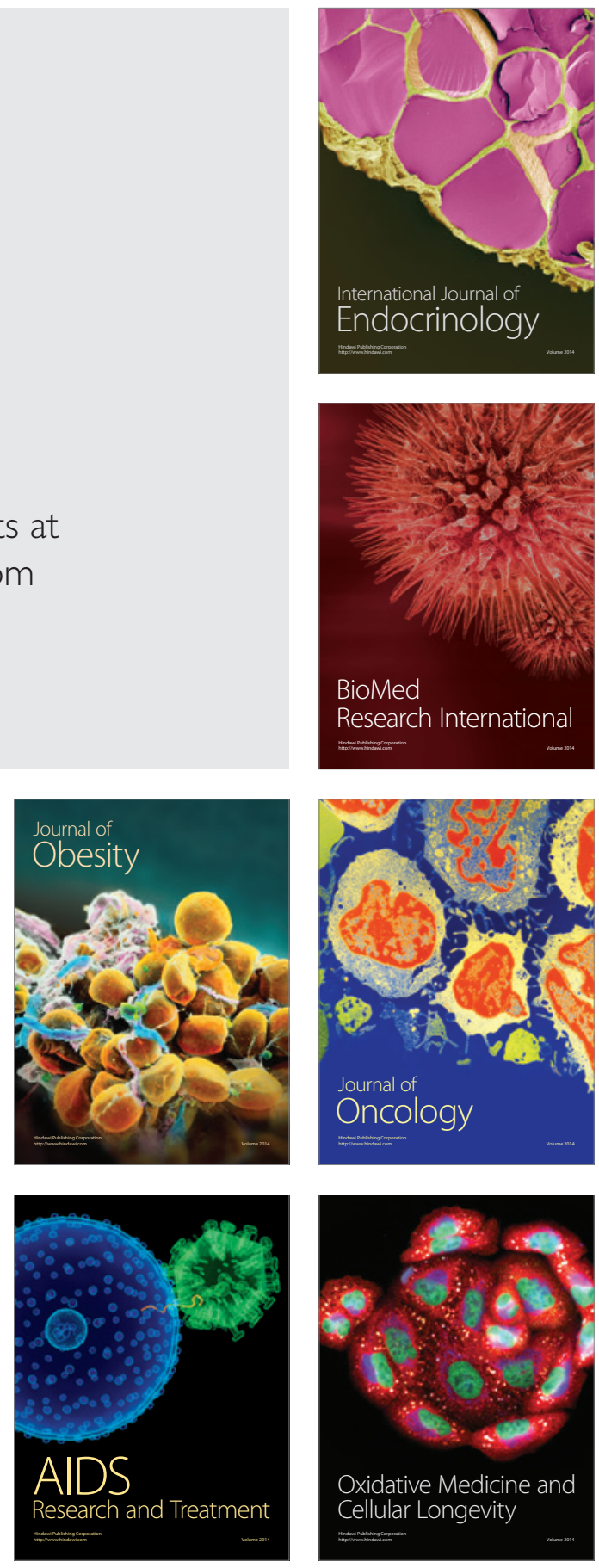